\title{
Non-Inferiority of Resolute Integrity Drug-Eluting Stent to Benchmark Xience Drug-Eluting Stent
}

\author{
Masato Nakamura, MD; Satoru Otsuji, MD; Yoshihisa Nakagawa, MD; \\ Yuji Oikawa, MD; Nobuo Shiode, MD; Masatoshi Miyahara, MD; Toshihito Furukawa; \\ Gaku Nakazawa, MD; Hiroyoshi Yokoi, MD on behalf of the PROPEL Investigators
}

\begin{abstract}
Background: The Resolute Integrity coronary drug-eluting stent (DES), the next evolution of the Resolute DES, is designed with thinner stent struts and continuous sinusoidal technology to further enhance performance. This study evaluated the performance of the Resolute Integrity DES compared with the historical performance of Xience V.
\end{abstract}

\begin{abstract}
Methods and Results: We assessed the safety, efficacy, and deliverability of Resolute Integrity compared with the Xience DES, the prespecified historical control, in PROPEL, a large, real-world prospective, single-arm, open-label study. A total of 1,204 subjects were enrolled in PROPEL and treated with the Resolute Integrity DES at 76 sites in Japan. Lesion and procedural success rates were $100 \%$ and $99 \%$, respectively. Patients were equally complex in the Resolute Integrity and Xience cohorts. At 1 year in the clinical-only cohort, the primary endpoint target lesion failure was 4.3\% (34/800) in the Resolute Integrity cohort compared with $8.5 \%$ $(97 / 1,142)$ in the Xience historical controls $(P<0.001$ for non-inferiority). Target vessel failure, major adverse cardiac events, target vessel myocardial infarction, and the composite cardiac death and target vessel myocardial infarction were all lower with Resolute Integrity compared with Xience, including in "high risk" patients.
\end{abstract}

Conclusions: In the large, prospective, multicenter PROPEL trial, the performance of the Resolute Integrity DES was non-inferior to that of the benchmark Xience DES used as a historical comparator.

Key Words: Drug-eluting stents; PROPEL; Resolute Integrity; Xience

$\mathbf{T}$ he 1st-generation drug-eluting stents (DES) significantly reduced the risk of in-stent restenosis as compared with bare metal stents, but were associated with an increased risk of late and very late stent thrombosis (ST), ${ }^{\mathbf{1} 2}$ likely related to delayed healing, inflammation, and neoatherosclerosis. ${ }^{3-9}$ This issue was addressed by 2nd-generation DES, which used anti-inflammatory polymer coatings to elute an antiproliferative drug. ${ }^{10,11}$ The RESOLUTE All-Comers trial demonstrated similar outcomes with the Resolute ${ }^{\mathrm{TM}}$ DES (Medtronic, Santa Rosa, CA, USA) and Xience ${ }^{\mathrm{TM}}$ DES (Abbott Vascular, Santa Clara, CA, USA). ${ }^{12,13}$ With the advent of 2nd-generation DES, they have been used in evermore complex procedures, making deliverability and the need to reduce the risk of procedural-related complications increasingly important. Percutaneous coronary intervention (PCI) is being offered to complex patient populations, such as those with diabetes mellitus, small coronary vessels and diffuse disease, total coronary occlusions, bifurcation lesions, and prior myocardial infarction (MI). ${ }^{13-16} \mathrm{We}$ assessed the safety, efficacy, and deliverability of the 3rd-generation Resolute Integrity ${ }^{\mathrm{TM}}$ DES (Medtronic) in a large, real-world patient population compared with a prespecified historical control, the Xience DES, from the RESOLUTE All-Comers trial.

\section{Methods}

\section{Device Description}

The Resolute Integrity DES is the subsequent iteration

Received January 9, 2018; revised manuscript received May 2, 2018; accepted May 23, 2018; released online July 3, 2018 Time for primary review: 34 days

Department of Cardiovascular Internal Medicine, Toho University Medical Center, Ohashi Hospital, Tokyo (M.N.); Department of Cardiovascular Internal Medicine, Higashi Takarazuka Satoh Hospital, Takarazuka (S.O.); Department of Cardiovascular Internal Medicine, Tenri Hospital, Tenri (Y.N.); Department of Cardiovascular Medicine, The Cardiovascular Institute, Tokyo (Y.O.); Department of Cardiovascular Internal Medicine, Tsuchiya General Hospital, Hiroshima (N.S.); Department of Cardiovascular Medicine, Mie Heart Center, Mie (M.M.); Biostatistical Research Center, Tokyo (T.F.); Department of Cardiovascular Internal Medicine, Tokai University Hospital, Isehara (G.N.); and Department of Cardiovascular Medicine, Fukuoka Sanno Hospital, Fukuoka (H.Y.), Japan

Clinical Trial Registration: URL: http://www.clinicaltrials.gov. Unique identifier: NCT01808391.

A complete list of investigators in the PROPEL trial is provided in Appendix S1.

Mailing address: Masato Nakamura, MD, Division of Cardiovascular Medicine, Toho University Ohashi Medical Center, 2-22-36 Ohashi, Meguro-ku, Tokyo 153-8515, Japan. E-mail: masato@oha.toho-u.ac.jp

ISSN-1346-9843 All rights are reserved to the Japanese Circulation Society. For permissions, please e-mail: cj@j-circ.or.jp 


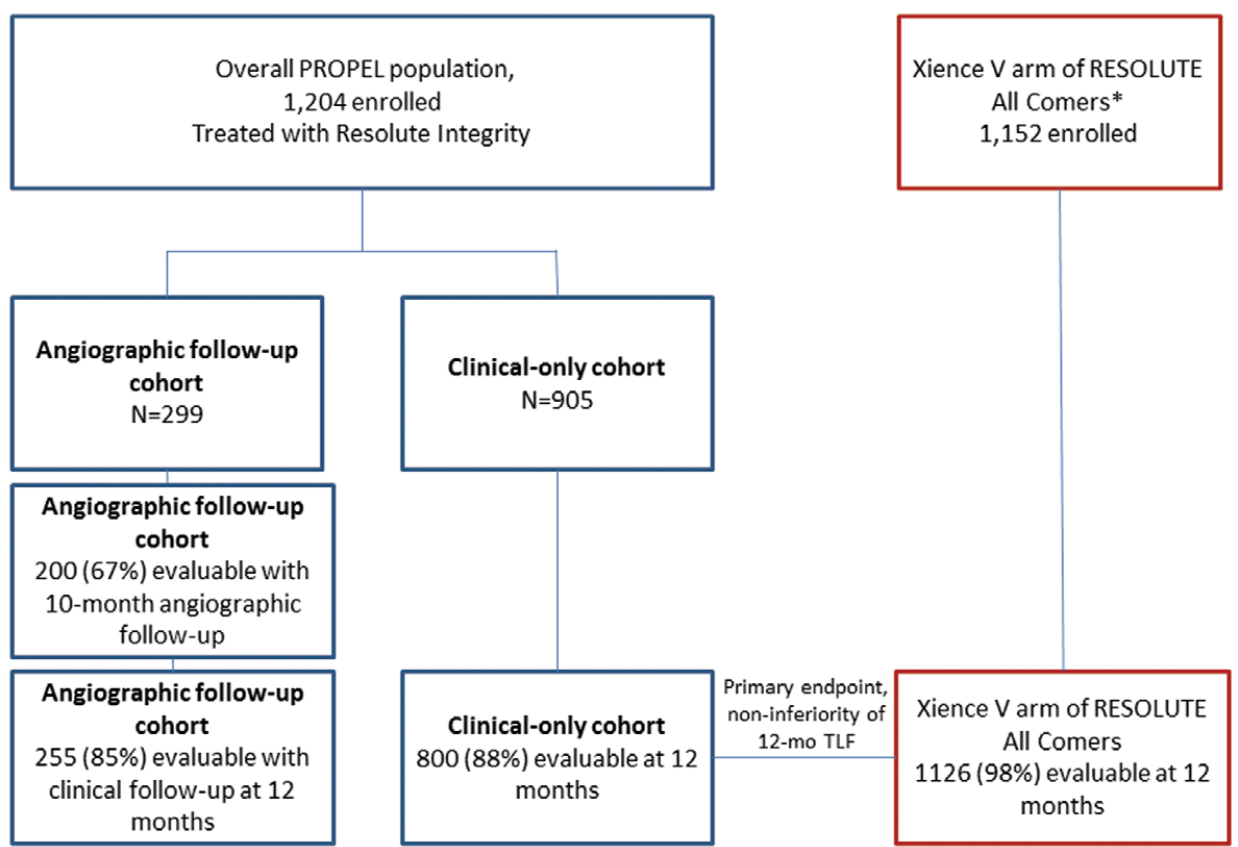

Figure 1. Patient disposition in PROPEL to 12 months. *Angiographic follow-up in RESOLUTE All-Comers occurred at 13 months. At 12 months, all RESOLUTE All-Comers patients had clinical-only follow-up.

\begin{tabular}{|c|c|c|c|}
\hline & $\begin{array}{l}\text { Resolute Integrity } \\
\qquad(n=905)\end{array}$ & $\begin{array}{c}\text { Xience } \\
(n=1,152)\end{array}$ & $P$ value \\
\hline Age (years) & $69.7 \pm 9.6$ & $64.2 \pm 10.8$ & $<0.001$ \\
\hline Male & $702(77.6)$ & $889(77.2)$ & 0.874 \\
\hline Diabetes mellitus & $377(41.7)$ & $270(23.4)$ & $<0.001$ \\
\hline Insulin-dependent & $69(7.6)$ & $82(7.1)$ & 0.671 \\
\hline History of hypertension & $734(81.1)$ & $821(71.3)$ & $<0.001$ \\
\hline History of hyperlipidemia & $685(75.7)$ & $780(67.7)$ & $<0.001$ \\
\hline Current smoker & $181(20.0)$ & $305(26.5)$ & $<0.001$ \\
\hline Prior Ml & $190 / 899(21.1)$ & $341 / 1,120(30.4)$ & $<0.001$ \\
\hline Prior $\mathrm{PCl}$ & $359(39.7)$ & $370(32.1)$ & $<0.001$ \\
\hline Prior CABG surgery & $34(3.8)$ & $110(9.5)$ & $<0.001$ \\
\hline LVEF $<30 \%$ & $16 / 797(2.0)$ & $13 / 608(2.1)$ & 0.853 \\
\hline Renal insufficiency (creatinine $\geq 140 \mu \mathrm{mol} / \mathrm{L}$ ) & $84 / 905(9.3)$ & $35 / 1,126(3.1)$ & $<0.001$ \\
\hline \multicolumn{4}{|l|}{ Reason for revascularization } \\
\hline Silent ischemia & $183(20.2)$ & $0(0.0)$ & $<0.001$ \\
\hline Stable angina & $416(46.0)$ & $416(36.1)$ & $<0.001$ \\
\hline Unstable angina & $152(16.8)$ & $218(18.9)$ & 0.225 \\
\hline Acute $\mathrm{Ml}$ ( $<72 \mathrm{~h}$ after onset of symptoms) & $97(10.7)$ & $332(28.8)$ & $<0.001$ \\
\hline ST-segment MI & 79/97 (81.4) & 186/332 (56.0) & $<0.001$ \\
\hline
\end{tabular}

Results presented as mean $\pm S D, n(\%)$, or $n / N(\%)$. CABG, coronary artery bypass graft; $L V E F$, left ventricular ejection fraction; Ml, myocardial infarction; $\mathrm{PCl}$, percutaneous coronary intervention.

of the Resolute DES and features continuous sinusoidal technology, in which a single continuous wire composed of a cobalt alloy has a sinusoidal design, wound around a mandrel, and then laser-fused at specific crowns to create its final shape. Resolute Integrity differs from conventional
DES, which are laser-cut tubes, and from the Resolute DES, which is formed by fusing together sinusoidal rings. Continuous sinusoidal technology is hypothesized to improve stent deliverability, reduce abrasion during delivery, and improve stent conformability and apposition to the 
Table 2. Baseline Lesions and Successful Procedural Outcomes in PROPEL, Stratified by All Patients and the Angiographic Cohort

\begin{tabular}{|c|c|c|}
\hline Lesion characteristics & $\begin{array}{c}\text { All patients } \\
\text { ( } n=1,204 \text { patients, } 1,522 \text { lesions) }\end{array}$ & $\begin{array}{l}\text { Angiographic follow-up cohort } \\
\text { ( } n=299 \text { patients, } 393 \text { lesions) }\end{array}$ \\
\hline \multicolumn{3}{|l|}{ Vessel location per lesion } \\
\hline Left anterior descending artery & $651(42.8)$ & $162(41.2)$ \\
\hline Left circumflex artery & $336(22.1)$ & $93(23.7)$ \\
\hline Right coronary artery & $496(32.6)$ & $128(32.6)$ \\
\hline Left main coronary artery & $36(2.4)$ & $10(2.5)$ \\
\hline Bypass graft & $3(0.2)$ & $0(0.0)$ \\
\hline Severe calcification & $165 / 1,484(11.1)$ & $33 / 362(9.1)$ \\
\hline Thrombolysis in Myocardial Infarction flow 0 & $147 / 1,494(9.8)$ & $34 / 372(9.1)$ \\
\hline Preprocedure reference vessel diameter, $\mathrm{mm}$ & $2.7 \pm 0.5$ & $2.8 \pm 0.5$ \\
\hline Long lesion ( $\geq 20 \mathrm{~mm}$ ) & $381 / 1,436(26.5)$ & $118 / 364(32.4)$ \\
\hline $\mathrm{AHA} / \mathrm{ACC} \mathrm{B} 2 / \mathrm{C}$ lesion & $1,193 / 1,500(79.5)$ & 213/337 (83.0) \\
\hline Patient SYNTAX score & $11.1 \pm 8.0$ & $10.5 \pm 7.8$ \\
\hline Chronic total occlusion & $64(5.3)$ & $19 / 373(5.1)$ \\
\hline \multicolumn{3}{|l|}{ Success } \\
\hline Lesion success & $1,494 / 1,494(100.0)$ & $373 / 373(100.0)$ \\
\hline Device success & $1,464 / 1,496(97.9)$ & $369 / 375(98.4)$ \\
\hline Procedural success & $1,171 / 1,179(99.3)$ & $281 / 281(100.0)$ \\
\hline
\end{tabular}

Results presented as mean \pm standard deviation or $n(\%)$. ACC, American College of Cardiology; AHA, American Heart Association.

\begin{tabular}{|l|}
\hline $\begin{array}{l}\text { Table 3. The 10-Month Angiographic Outcomes in the } \\
\text { PROPEL Angiographic Cohort } \\
\text { Angiographic cohort } \\
\text { (n=254 lesions) }\end{array}$ \\
Diameter stenosis, \% \\
In-segment \\
In-stent \\
Late lumen loss, mm \\
In-segment \\
In-stent \\
Minimal lumen diameter, mm \\
In-segment \\
In-stent \\
Binary restenosis rate, \% \\
In-segment \\
In-stent \\
\hline
\end{tabular}

Results presented as mean \pm SD or \% (n).

vessel wall. Similar to the Resolute DES, the Resolute Integrity DES utilizes the biocompatible polymer BioLinx ${ }^{\mathrm{TM}}$, which has been shown in preclinical studies to elicit minimal inflammatory response, ${ }^{17-19}$ and therefore retains the same drug elution characteristics.

\section{Study Design}

The Prospective Multicenter Post-Approval Study to Evaluate the Long-Term Efficacy and Safety of the Resolute Integrity in Japanese All-Comers Patients With Coronary Artery Disease (PROPEL) is a multicentre, prospective, historical control study in an all-comer population. The primary endpoint is 12-month target lesion failure (TLF) with Resolute Integrity compared with a prespecified historical control, the Xience V DES arm in the RESOLUTE All-Comers trial.12,13 Because patients in Japan typically undergo angiographic follow-up before 12 months, an angiographic follow-up cohort was established, with angiographic follow-up scheduled at 10 months post-implantation. However, angiographic follow-up in RESOLUTE All-Comers was not performed until 13 months. Therefore, outcomes after implantation with Resolute Integrity in the PROPEL clinical-only cohort are compared with those from the Xience arm in RESOLUTE All-Comers (Figure 1).

\section{Patient Population}

Minimal inclusion and exclusion criteria were applied in PROPEL. Patients were $>20$ and $<85$ years old with symptomatic coronary artery disease (i.e., clinical indication for PCI with at least 1 coronary lesion visually confirmed on angiography with $>50 \%$ diameter stenosis). Vessel diameter was required to be $2.5-3.5 \mathrm{~mm}$. Exclusion criteria included cardiogenic shock, contraindications for aspirin or clopidogrel, pregnancy, and planned or elective surgery within 6 months of PCI. Dual-antiplatelet therapy (DAPT) was recommended for at least 6 months after stent implantation. Clinical follow-up occurred at 30 days and 9 and 12 months in all patients, and angiographic follow-up in the angiographic cohort at 10 months.

\section{Study Funding and Oversight}

The PROPEL trial was funded by Medtronic Japan and sponsored by the Associations for Establishment of Evidence in Interventions (Tokyo, Japan), which oversaw the study. The study complied with the Declaration of Helsinki, and was approved by the appropriate institutional review board at each study center. Written informed consent was given by all patients. The study included an executive operation committee, a data monitoring committee, and an independent clinical event committee. The data coordinating center (Soiken, Inc., Tokyo, Japan) provided all of the site monitoring. The angiographic core laboratory (Cardiovascular Imaging Core Laboratory, Tokyo, Japan) measured all angiographic endpoints (at both baseline and at 10 months). 


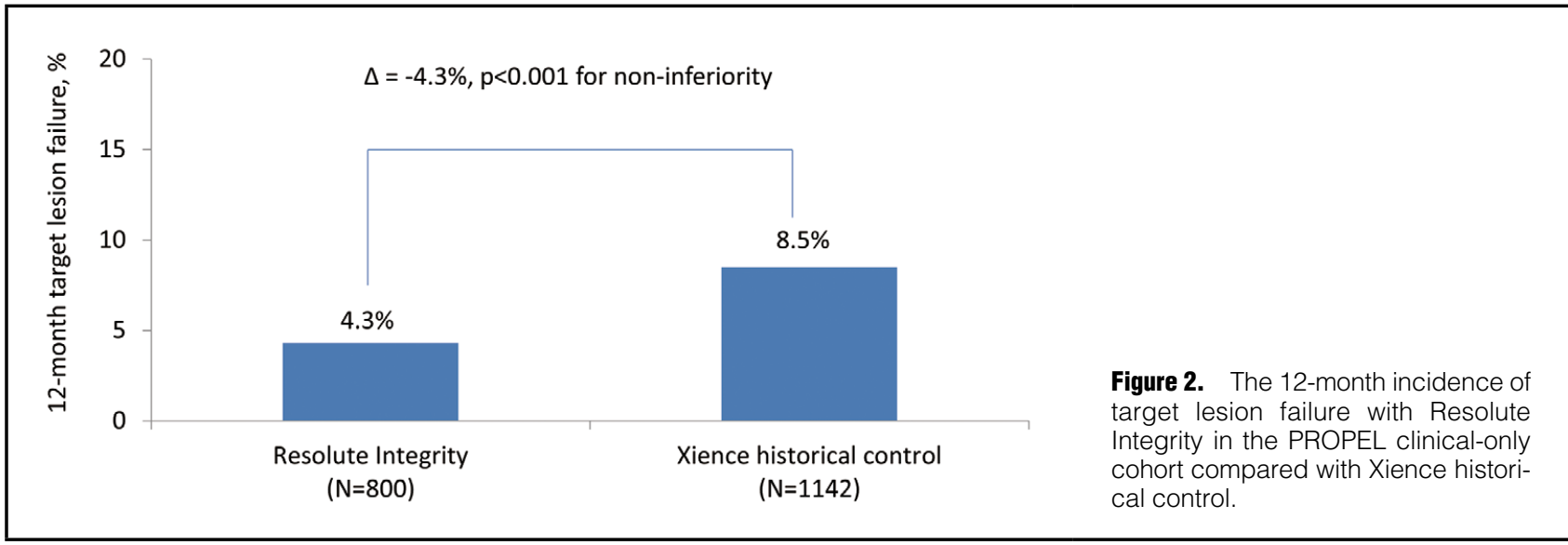

\begin{tabular}{|c|c|c|c|}
\hline & $\begin{array}{l}\text { Resolute integrity } \\
(n=800)\end{array}$ & $\begin{array}{c}\text { Xience } \\
(n=1,142)\end{array}$ & P value* \\
\hline Target lesion failure & $34(4.3)$ & $97(8.5)$ & $<0.001$ \\
\hline Target vessel failure & $41(5.1)$ & $111(9.7)$ & $<0.001$ \\
\hline Major adverse cardiac events & $42(5.3)$ & $112(9.8)$ & $<0.001$ \\
\hline Cardiac death or target vessel myocardial infarction & $9(1.1)$ & $63(5.5)$ & $<0.001$ \\
\hline Death & $15(1.9)$ & $31(2.7)$ & 0.289 \\
\hline Cardiac death & $8(1.0)$ & $19(1.7)$ & 0.243 \\
\hline Noncardiac death & $7(0.9)$ & $12(1.1)$ & 0.817 \\
\hline Target vessel myocardial infarction & $1(0.1)$ & $48(4.2)$ & $<0.001$ \\
\hline Clinically driven target lesion revascularization & $26(3.3)$ & $39(3.4)$ & 0.898 \\
\hline Clinically driven target vessel revascularization & $33(4.1)$ & $55(4.8)$ & 0.507 \\
\hline Major bleeding & $4(0.5)$ & NA & NA \\
\hline Academic Research Consortium definite/probable stent thrombosis & $2(0.3)$ & $8(0.7)$ & 0.212 \\
\hline Definite & $2(0.3)$ & $3(0.3)$ & 1.000 \\
\hline Probable & $0(0.0)$ & $5(0.4)$ & 0.082 \\
\hline
\end{tabular}

Results presented as $\mathrm{n}(\%)$. * $\mathrm{P}$ value adjusted by a prespecified propensity score model as defined in the Methods section.

\section{Endpoint Definitions}

All endpoints were defined identically to those in the RESOLUTE All-Comers trial.12,13 TLF was defined as cardiac death, target vessel MI (TV-MI), or clinically driven target lesion revascularization (TLR). Target vessel failure (TVF) was defined as cardiac death, MI, or clinically driven target vessel revascularization by percutaneous or surgical methods. Major adverse cardiac events (MACE) were defined as all-cause death, MI, emergency coronary artery bypass surgery, or repeat clinically indicated TLR by percutaneous or surgical method. ST was defined according to the Academic Research Consortium (ARC) definition. ${ }^{20}$ Major bleeding was defined by the Randomized Evaluation in PCI Linking Angiomax to Reduced Clinical Events (REPLACE-2) trial definition. ${ }^{21}$ Patients were categorized as "high risk" if they met at least 1 of the following criteria: diabetes mellitus, previous MI, previous coronary revascularization, renal insufficiency (creatinine level $\geq 140 \mu \mathrm{mol} / \mathrm{L}$ ), left ventricular ejection fraction $\leq 30 \%$, and age $\geq 75$ years. This definition was based on patient characteristics found to pose high risk for cardiovascular events in past studies of PCI. ${ }^{22-25}$
Lesion success was defined as attainment of $<50 \%$ residual stenosis of the target lesion using any percutaneous method. Device success was defined as lesion success using only the Resolute Integrity stent. Procedural success was defined as lesion success and no in-hospital MACE.

\section{Statistical Analysis}

This trial was powered for a prespecified non-inferiority testing of TLF at 12 months comparing Resolute Integrity in the clinical-only cohort to a historical control, the Xience arm in the RESOLUTE All-Comers trial, with a non-inferiority margin of $3.5 \%$ after propensity score adjustment. The TLF rate observed in the historical control was $8.5 \%(97 / 1,142)$. Assuming the TLF rate in the Resolute Integrity arm would be the same as in the historical control, with a 1-sided type I error of 0.05 , a total of 900 patients in the clinical cohort yielded $84 \%$ power to demonstrate non-inferiority, assuming a 10\% lost-to-follow-up rate. Given possible differences in the baseline characteristics of patients treated with Resolute Integrity and those treated with Xience, a prespecified propensity score-adjusted model was used for comparisons of Resolute Integrity to 

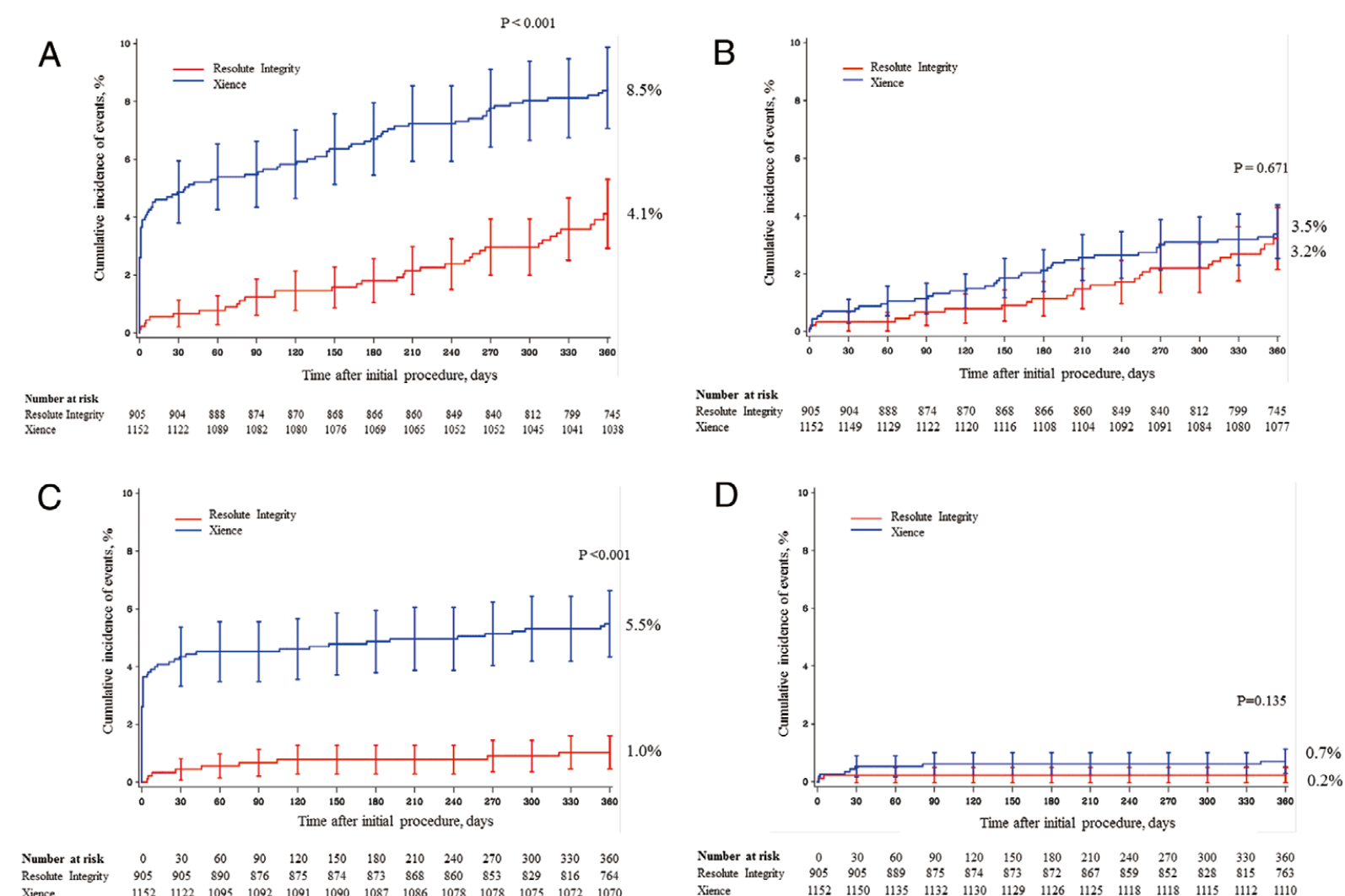

$\begin{array}{lccccccccccccc}\text { Number at risk } & 0 & 30 & 60 & 90 & 120 & 150 & 180 & 210 & 240 & 270 & 300 & 330 & 360 \\ \text { Resolute Integrity } & 905 & 905 & 890 & 876 & 875 & 874 & 873 & 868 & 860 & 853 & 829 & 816 & 764\end{array}$ $\begin{array}{llllllllllllll}\text { Resolute Integnity } & 905 & 905 & \$ 90 & \$ 16 & 875 & 814 & 873 & 868 & 860 & 853 & \$ 29 & 816 & 764 \\ \text { Xience } & 1152 & 1122 & 1095 & 1092 & 1091 & 1090 & 1087 & 1086 & 1078 & 1078 & 1075 & 1072 & 1070\end{array}$

Figure 3. The 12-month cumulative incidence of cardiovascular events with the Resolute Integrity in the PROPEL clinical-only cohort compared with Xience historical control. (A) TLF. (B) Clinically driven TLR. (C) Cardiac death or target vessel MI. (D) ARC definite or probable stent thrombosis. ARC, Academic Research Consortium; TLF, target lesion failure; TLR, target lesion revascularization.

Xience, including in the P-value for non-inferiority (and superiority) of Resolute Integrity to Xience. The following baseline variables were used for propensity score calculations: age, male sex, diabetes mellitus, prior MI, lesion length, preprocedure reference vessel diameter, and SYNTAX score. ${ }^{26}$

All analyses were conducted on an intention-to-treat basis. Continuous parameters are presented as mean $\pm \mathrm{SD}$; nominal parameters as counts and percentages. The 12-month cumulative incidence of clinical events was assessed according to Kaplan-Meier estimates and compared with the Xience historical arm using the log-rank test. $\mathrm{P}<0.05$ was considered statistically significant. Analyses were performed using SAS software, version 9.1 or later (SAS Institute, Cary, NC, USA).

\section{Results}

The PROPEL trial enrolled 1,204 patients with coronary artery disease from 76 sites between February 2013 and September 2014. The first 905 patients were enrolled in the clinical-only cohort, and the remaining 299 patients in the routine angiographic cohort. Patient disposition is shown in Figure 1.

Table 1 provides baseline patient and lesion characteristics and acute success with Resolute Integrity in the clini- cal-only cohort compared with the Xience historical control. Both cohorts were equally complex. Patients in the Resolute Integrity cohort were more likely to be older, have diabetes mellitus, a history of hypertension, hyperlipidemia, prior PCI, and longer lesions, but less likely to have prior MI, prior coronary artery bypass graft surgery, revascularization because of acute MI, and severely calcified lesions. Baseline patient characteristics of all PROPEL patients and those in the angiographic follow-up cohort are shown in Table S1.

Baseline lesion characteristics and acute success in all PROPEL patients and in the angiographic follow-up cohort are shown in Table 2. All lesions were successfully crossed (100\% lesion success); device and procedural success rates with Resolute Integrity were $97.9 \%$ and $99.3 \%$, respectively. At 10 months, in-segment and in-stent late lumen losses in the angiographic cohort were $0.16 \pm 0.37$ and $0.26 \pm 0.4 \mathrm{~mm}$, respectively (Table 3 ).

The primary endpoint, 12-month TLF in the clinicalonly cohort compared with the Xience historical control, was $4.3 \%(34 / 800)$ vs. $8.5 \%(97 / 1,142)$; the upper bound of the 1 -sided $95 \%$ confidence interval $(\mathrm{CI})$ was $-2.2 \%$ and less than the prespecified upper bound of $3.5 \%(\mathrm{P}<0.001$ for non-inferiority; Figure 2).

Compared with Xience, Resolute Integrity was also associated with a lower rate of TVF, MACE, target vessel 


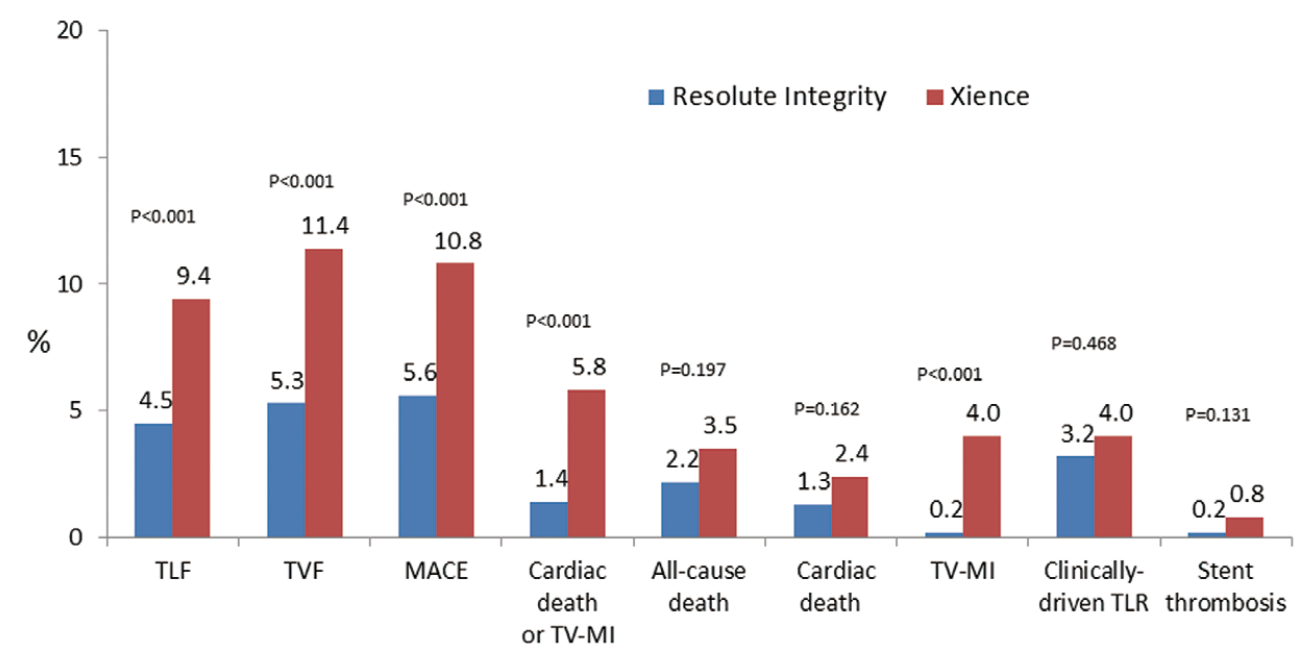

Figure 4. The 12-month incidence of cardiovascular events in high-risk patients treated with Resolute Integrity in the PROPEL clinical-only cohort compared with historical control Xience. P values were adjusted by a prespecified propensity score model as defined in Methods. MACE, major adverse cardiac events; TLR, target lesion revascularization; TV-MI, target vessel myocardial infarction; TVF, target vessel failure. Stent thrombosis defined by Academic Research Consortium definite or probable stent thrombosis.

MI, and the composite of cardiac death and TV-MI (Table 4). The cumulative incidence of TLF and its components, clinically driven TLR, and cardiac death/target vessel MI, as well as ARC definite or probable ST, are shown in Figure 3.

TLF was low across complex subsets, including patients with diabetes mellitus, ST-segment MI, bifurcation lesions, and small vessel treatment (Figure S1). The 12-month incidence of TLF with Resolute Integrity in the clinical-only cohort compared with the Xience historical control was $5.4 \%$ vs. $9.0 \%$ (odds ratio, $0.6 ; 95 \% \mathrm{CI}, 0.3-1.1$ ) in patients with diabetes mellitus and $5.9 \%$ vs. $11.4 \%$ (odds ratio, 0.5 ; 95\% CI, 0.2-1.0) in patients treated for a bifurcation lesion. Furthermore, $78 \%$ of the clinical-only cohort and $63 \%$ of the historical control cohort were considered high-risk patient populations, as defined in the Methods. In these high-risk patient populations at 12 months, Resolute Integrity was associated with a lower incidence of TLF compared with Xience ( $4.5 \%$ vs. $9.4 \%, \mathrm{P}<0.001)$, as well as lower incidences of TVF, MACE, target vessel MI, and the composite cardiac death/TV-MI (Figure 4).

DAPT usage at 30 days, 6 months, and 12 months was $97 \%, 95 \%$, and $79 \%$, respectively. The 1 -year ARC definite early ST was $0.3 \%(3 / 1,072)$. All 3 cases were definite ST before 30 days; no cases of ST occurred between 30 days and 12 months. The 12-month incidence of cardiovascular events was similar in patients treated in the clinical-only and angiographic cohorts ( $4.3 \%$ vs. $5.5 \%, \mathrm{P}=0.392)$.

\section{Discussion}

The PROPEL study is the first large, prospective, multicenter study to investigate the long-term clinical outcomes of Resolute Integrity in a real-world patient population. The primary outcome, 12 -month TLF, was $4.3 \%$ with Resolute Integrity vs. $8.5 \%$ with Xience $(\Delta=-4.2 \%$, $\mathrm{P}<0.001$ for non-inferiority). The low rate of $4.3 \% \mathrm{TLF}$ in
PROPEL was driven by a very low rate of $0.2 \%$ for target vessel MI, compared with a TV-MI rate of $4.0 \%$ for Xience in the historical control. This difference could be attributed to differences in procedural technique between Japan and Europe, although this is speculative. In addition, TVF, MACE, and the composite cardiac death and target vessel revascularization were all lower with Resolute Integrity compared with the historical control Xience. This difference in cardiovascular outcomes was also observed in highrisk patients.

Lesion success in PROPEL with Resolute Integrity was $100 \%$. The low in-hospital MI rate in PROPEL contributed to the improvement in procedural success, which was $99 \%$ with Resolute Integrity. This high procedural success is similar to that observed in other studies of Resolute Integrity, including the all-comer trial Deliverability of the Resolute Integrity Stent in All-Comer Vessels and Cross-over Stenting (DELIVER; 97.9\%), ${ }^{27}$ and An Evaluation of the Commercially Available Medtronic Resolute Integrity Zotarolimus-Eluting Coronary Stent System (RESOLUTE Integrity US; $98.2 \%) .{ }^{28}$ Procedural success appeared to be higher than that observed with the previous-generation Resolute DES or with current-generation Xience DES, including in RESOLUTE All-Comers (94.6\% and 94.2\%, respectively)..$^{13}$

The 12-month TLF with Resolute Integrity in PROPEL remained low across complex subgroups and numerically lower than that observed with Xience in RESOLUTE All-Comers, including in the majority of complex subsets. It is often in these more complex patient subsets that improving lesion crossability and minimizing plaque abrasion during stent delivery are most important.

Furthermore, TLF with Resolute Integrity was similar in patients with non-insulin-dependent diabetes mellitus and those without diabetes mellitus, as well as in patients who presented with ST-segment elevation MI and those who did not. This has been observed with its predecessor 
Resolute DES, ${ }^{29,30}$ and may in part be related to the nonthrombogenic BioLinx polymer used in both stents. ${ }^{17}$ The low rates of cardiovascular events in PROPEL may also be related to the Japanese operators, as Japanese operators are known to have high procedural success rates, including successful recanalization of chronic total occlusions of $\approx 90 \%$ (even in low-volume centers). ${ }^{31}$

\section{Study Limitations}

The primary endpoint used a prespecified historical control. Although both populations were similarly complex, the PROPEL study was conducted in Japan, whereas the RESOLUTE All-Comers study was conducted in Europe and regional differences in procedural techniques and patient populations may have affected outcomes. Results were not adjusted for differences in procedural technique such as IVUS-guided PCI vs. angio-guided PCI, use of post-dilatation, or amount of stent inflation pressure applied, and these differences may have influenced outcomes.

\section{Conclusions}

The PROPEL study is the first large, prospective, multicenter study to investigate the long-term clinical outcomes of the Resolute Integrity DES in a real-world patient population. Performance of the Resolute Integrity stent was non-inferior to the benchmark Xience DES used as historical comparator. Lesion and procedural success rates with Resolute Integrity were $100 \%$ and $99 \%$, respectively. Cardiovascular events with Resolute Integrity in PROPEL were low across complex subgroups.

\section{Conflict of Interest Statement}

S.O. has consultancy agreements with Asahi Intecc and Goodman Nipro, and receives speaker fees from Boston Scientific and Abbott. All other authors have nothing to disclose. All authors have approved the final article.

\section{Funding}

The PROPEL trial was funded by Medtronic Japan Co., Ltd., and sponsored by the Associations for Establishment of Evidence in Interventions (Tokyo, Japan), which oversaw the study.

\section{References}

1. Stone GW, Ellis SG, Cox DA, Hermiller J, O'Shaughnessy C, Mann JT, et al. A polymer-based, paclitaxel-eluting stent in patients with coronary artery disease. $N$ Engl J Med 2004; 350: $221-231$.

2. Lagerqvist B, Carlsson J, Frobert O, Lindback J, Schersten F, Stenestrand U, et al. Stent thrombosis in Sweden: A report from the Swedish Coronary Angiography and Angioplasty Registry. Circ Cardiovasc Interv 2009; 2: 401-408.

3. Nakazawa G, Otsuka F, Nakano M, Vorpahl M, Yazdani SK, Ladich $\mathrm{E}$, et al. The pathology of neoatherosclerosis in human coronary implants bare-metal and drug-eluting stents. $\mathrm{J} \mathrm{Am} \mathrm{Coll}$ Cardiol 2011; 57: 1314-1322.

4. Finn AV, Joner M, Nakazawa G, Kolodgie F, Newell J, John MC, et al. Pathological correlates of late drug-eluting stent thrombosis: Strut coverage as a marker of endothelialization. Circulation 2007; 115: 2435-2441.

5. Joner M, Finn AV, Farb A, Mont EK, Kolodgie FD, Ladich E, et al. Pathology of drug-eluting stents in humans: Delayed healing and late thrombotic risk. J Am Coll Cardiol 2006; 48: 193-202.

6. Virmani R, Guagliumi G, Farb A, Musumeci G, Grieco N, Motta $\mathrm{T}$, et al. Localized hypersensitivity and late coronary thrombosis secondary to a sirolimus-eluting stent: Should we be cautious? Circulation 2004; 109: 701-705.

7. Togni M, Raber L, Cocchia R, Wenaweser P, Cook S, Windecker $\mathrm{S}$, et al. Local vascular dysfunction after coronary paclitaxel-eluting stent implantation. Int J Cardiol 2007; 120: 212-220.
8. Togni M, Windecker S, Cocchia R, Wenaweser P, Cook S, Billinger $\mathrm{M}$, et al. Sirolimus-eluting stents associated with paradoxic coronary vasoconstriction. J Am Coll Cardiol 2005; 46: 231 - 236.

9. Pendyala LK, Yin X, Li J, Chen JP, Chronos N, Hou D. The first-generation drug-eluting stents and coronary endothelial dysfunction. JACC Cardiovasc Interv 2009; 2: 1169-1177.

10. Tada T, Byrne RA, Simunovic I, King LA, Cassese S, Joner M, et al. Risk of stent thrombosis among bare-metal stents, firstgeneration drug-eluting stents, and second-generation drugeluting stents: Results from a registry of 18,334 patients. JACC Cardiovasc Interv 2013; 6: 1267-1274.

11. Palmerini T, Biondi-Zoccai G, Della Riva D, Mariani A, Sabate $\mathrm{M}$, Valgimigli M, et al. Clinical outcomes with drug-eluting and bare-metal stents in patients with ST-segment elevation myocardial infarction: Evidence from a comprehensive network metaanalysis. J Am Coll Cardiol 2013; 62: 496-504.

12. Iqbal J, Serruys PW, Silber S, Kelbaek H, Richardt G, Morel MA, et al. Comparison of zotarolimus- and everolimus-eluting coronary stents: Final 5-year report of the RESOLUTE allcomers trial. Circ Cardiovasc Interv 2015; 8: e002230.

13. Serruys PW, Silber S, Garg S, van Geuns RJ, Richardt G, Buszman $\mathrm{PE}$, et al. Comparison of zotarolimus-eluting and everolimuseluting coronary stents. $N$ Engl J Med 2010; 363: 136-146.

14. Smits PC, Vlachojannis GJ, McFadden EP, Royaards KJ, Wassing J, Joesoef KS, et al. Final 5-year follow-up of a randomized controlled trial of everolimus- and paclitaxel-eluting stents for coronary revascularization in daily practice: The COMPARE trial (a trial of everolimus-eluting stents and paclitaxel stents for coronary revascularization in daily practice). JACC Cardiovasc Interv 2015; 8: 1157-1165.

15. Kelbaek H, Holmvang L, Richardt G, Eberli FR, Stella P, Buszman PE, et al. Clinical results with the resolute zotarolimuseluting stent in total coronary occlusions. EuroIntervention 2015; 11: $650-657$.

16. Ferenc M, Kornowski R, Belardi J, Serruys P, Silber S, Widimsky $P$, et al. Three-year outcomes of percutaneous coronary intervention with next-generation zotarolimus-eluting stents for de novo coronary bifurcation lesions. J Invasive Cardiol 2014; 26: 630638.

17. Udipi K, Melder RJ, Chen M, Cheng P, Hezi-Yamit A, Sullivan $\mathrm{C}$, et al. The next generation Endeavor Resolute stent: Role of the Biolinx Polymer System. EuroIntervention 2007; 3: 137-139.

18. Meredith IT, Worthley S, Whitbourn R, Walters D, Popma J, Cutlip D, et al. The next-generation Endeavor Resolute stent: 4-month clinical and angiographic results from the Endeavor Resolute first-in-man trial. EuroIntervention 2007; 3: 50-53.

19. Hezi-Yamit A, Sullivan C, Wong J, David L, Chen M, Cheng P, et al. Impact of polymer hydrophilicity on biocompatibility: Implication for DES polymer design. J Biomed Mater Res A 2009; 90: $133-141$.

20. Cutlip DE, Windecker S, Mehran R, Boam A, Cohen DJ, van Es GA, et al. Clinical end points in coronary stent trials: A case for standardized definitions. Circulation 2007; 115: 2344-2351.

21. Lincoff AM, Kleiman NS, Kereiakes DJ, Feit F, Bittl JA, Jackman JD, et al. Long-term efficacy of bivalirudin and provisional glycoprotein IIb/IIIa blockade vs. heparin and planned glycoprotein IIb/IIIIa blockade during percutaneous coronary revascularization: REPLACE-2 randomized trial. JAMA 2004; 292: 696-703.

22. Abdel-Wahab M, Neumann FJ, Serruys P, Silber S, Leon M, Mauri L, et al. Incidence and predictors of unplanned non-target lesion revascularisation up to three years after drug-eluting stent implantation: Insights from a pooled analysis of the RESOLUTE Global Clinical Trial Program. EuroIntervention 2016; 12: $465-$ 472.

23. Iqbal J, Gunn J, Serruys PW. Coronary stents: Historical development, current status and future directions. Br Med Bull 2013; 106: $193-211$

24. Lee JM, Park KW, Han JK, Yang HM, Kang HJ, Koo BK, et al. Three-year patient-related and stent-related outcomes of second-generation everolimus-eluting xience $\mathrm{V}$ stents versus zotarolimus-eluting resolute stents in real-world practice (from the Multicenter Prospective EXCELLENT and RESOLUTE-Korea Registries). Am J Cardiol 2014; 114: 1329-1338.

25. Stolker JM, Cohen DJ, Kennedy KF, Pencina MJ, Lindsey JB, Mauri L, et al. Repeat revascularization after contemporary percutaneous coronary intervention: An evaluation of staged, target lesion, and other unplanned revascularization procedures during the first year. Circ Cardiovasc Interv 2012; 5: 772-782.

26. Sianos G, Morel MA, Kappetein AP, Morice MC, Colombo A, 
Dawkins K, et al. The syntax score: An angiographic tool grading the complexity of coronary artery disease. EuroIntervention 2005; 1: 219-227.

27. Polad J, Wohrle J, Singh B, Chag M, Rha SW, Malik FT, et al. Deliverability of the Resolute integrity stent and a post hoc comparison of radial and femoral access: The DELIVER study. Cardiovasc Revasc Med 2014; 15: 289-294.

28. Caputo R. Evaluation of two-year outcomes following resolute integrity zotarolimus-eluting stent implantation [abstract TCT576]. JACC 2015; 66(15 Suppl B): B233.

29. Silber S, Serruys PW, Leon MB, Meredith IT, Windecker S, Neumann FJ, et al. Clinical outcome of patients with and without diabetes mellitus after percutaneous coronary intervention with the resolute zotarolimus-eluting stent: 2-year results from the prospectively pooled analysis of the international global RESOLUTE program. JACC Cardiovasc Interv 2013; 6: $357-$ 368.

30. Di Mario C, Windecker S. Tct-24 long-term clinical outcomes for primary angioplasty with Resolute zotarolimus eluting stent in ST-segment elevation acute myocardial infarction (abstract). $J$ Am Coll Cardiol 2014; 64: B8.
31. Habara M, Tsuchikane E, Muramatsu T, Kashima Y, Okamura A, Mutoh M, et al. Comparison of percutaneous coronary intervention for chronic total occlusion outcome according to operator experience from the Japanese Retrograde Summit registry. Catheter Cardiovasc Interv 2016; 87: 1027-1035.

\section{Supplementary Files}

\section{Supplementary File 1}

\section{Appendix S1. PROPEL Principal Investigators and Affiliations}

Figure S1. Forrest plot for the comparison of Resolute Integrity in the PROPEL clinical-only cohort compared with Xience historical control in 12-month target lesion failure across patient subsets.

Table S1. Baseline characteristics of subjects in PROPEL, stratified by all patients and the angiographic cohort

Please find supplementary file(s);

http://dx.doi.org/10.1253/circj.CJ-18-0011 